\title{
When narratives matter: men, sport, and spinal cord injury
}

\author{
A C Sparkes, B Smith
}

J Med Ethics; Medical Humanities 2005;31:81-88. doi: 10.1136/jmh.2005.000203

Experiencing a spinal cord injury (SCl) and becoming disabled through sport is a major disruptive life event that instigates a multiplicity of difficult and complex issues that the person has to deal with. One of these problems is how to restory a life and construct new body/self relationships and identities over time. To explore this process, we focus on the life stories of a small group of men $(n=14)$ who have suffered $\mathrm{SCl}$ and become disabled through playing rugby football. We illustrate the ways in which certain metaphors, notions of time, and kinds of hope, congregate and coalesce within three specific narrative types and how these operate to shape the individual experiences of these men following SCl. The implications of this dynamic process for the storied body/self and identity construction are highlighted throughout.

See end of article for authors' affiliations

.....................

Correspondence to: A C Sparkes, Qualitative Research Unit, School Sport and Health Sciences, St Luke's Campus, University of Exeter, Heavitree Road, Exeter, Devon, EX1 2LU, UK; A.C. Sparkes@exeter.ac.uk

Received 7 March 2005 Accepted for publication 16 March 2005 in magine having a life story that in the telling involves being a fit, able bodied, young man with a disciplined and dominating body as described by Frank ${ }^{1}$ who loves playing sport, and rugby union football in particular. ${ }^{\text {i }}$

Also imagine a life story in which, over the years, the central themes have revolved around the development of a strong athletic identity and a sense of self based on a performing body. ${ }^{\text {ii }}$

Now imagine this.

In the first half [of the rugby match], the centre shoulder charged me out off the pitch. It was a challenge really. I landed heavily on my left shoulder, it hurt like hell but I was only out on the wing anyway. It was an important game, we had no replacements so I struggled on until half time and had a bit of a rub down. I thought "Well I can manage". But, at the time when he shoulder charged me out, I got up and thought "All right sunshine, we've got another half to go yet".

In the second half, we turned up the pressure. It must have been about five or 10 minutes to go until the end of the match [silence for eight seconds]. We were winning, my shoulder was still giving me iip, so I could have come off really. But, it was pay back time and I won't forget it. I remember they were coming at us, they were in their own half, there was I on the wing and he [the centre] was outside. I should have been marking my own wing but for some reason I decided it was time to get him back. So I came inside, which I shouldn't have, I don't know why, I was never a dirty player. I don't know why, but we were both running at quite a speed towards each other and for some reason I was going to take him high, which I never thought I played like that before in all the years. I'd had a few fights yeah, sometimes come off for them, but that's just the way I am - I take the rough with the smooth...Then, then, [silence-five seconds], then as he [the centre] got closer and closer, in a very split second I changed my mind, sort of changed my position, just fractionally. This was in a split second, he dipped his shoulder at the same time as I lowered my position and his shoulder hit me straight on the top of my head. It was a bang against a brick wall really. There was no pain or nothing, just sounded like the crack of a gun going off. And the next minute I was lying on the floor saying: "Can you put my arms and legs down on the floor". Strange thing to say, strange thing to feel because my arms and legs felt as if they were raised to the sky and yet it never dawned on me at first that I couldn't feel the rest of my body... It just never dawned on me that maybe I was paralysed... When I had my accident I thought: "Bloody hell lads, is that happening really?" It's like being struck by lightning... It's difficult to put it into words really.

This is the moment, immortalised in time, ${ }^{3}$ when Jamie, a husband, father of three children, crane driver, and dedicated rugby player suffered a spinal cord injury (SCI) at the T2 level ${ }^{\mathrm{iii}}$ that propelled him from the world of the able bodied into the world of the disabled.

Abbreviations: $\mathrm{SCl}$, spinal cord injury

i The disciplined body presents itself as highly controlled and predictable and as lacking desire to engage and commune with other bodies. It is also dissociated from itself and isolated in its own performance even though this performance might be part of a collective institutional activity such as sport. The dominating body defines itself by force. It meets the challenge of events, like sport or SCl, by trying to beat it. The voice and narrative is dominated not by resignation or an imperative to develop the self, but by anger and frustration. It is also dissociated from itself and lacks desire, but it is dyadic in how it relates to other bodies. Thus, rather than communing with other bodies, it displaces its anger and frustration against its own limits on to others.

iithletic identity refers to the degree to which an individual identifies with the athlete role. ${ }^{2}$

iii " $\mathrm{T}$ " denotes thoracic vertebrae, and the " 2 " indicates the neurological level of damage. 
The severity of his spinal trauma is such that he now requires artificial life support and breathes using a ventilator. Jamie has no sensation or movement below the neck. Shortly after the SCI, Jamie's wife divorced him. He is currently unemployed, lives in a new bungalow, his children visit him fortnightly, and he has two female care assistants. Concisely, in a turning point moment Jamie's life story changed dramatically. And, even though he states: "It's difficult to put it into words really", this is exactly what he does as he constructs an autobiographical story postSCI to make sense of who he was, who he is now, and who he might be in the future.

According to Medved and Brockmeier, ${ }^{4}$ autobiographical stories are self narratives by which we give situation specific answers to the questions: "Who am I?" and "What is my life about?" In telling such stories, "people give meaning to their experiences within the flow and continuously changing contexts of life...All this is done not only in narratives about the past and the present, but also about future times and places" (Medved et al, ${ }^{4} \mathrm{p}$ 747). As these stories of a life are told they operate to provide a structure for our very sense of selfhood and identity. ${ }^{5}$ Indeed, for Brockmeier and Carbaugh, "the self in time-can only exist as a narrative construction". ${ }^{6}$

Personal stories based on remembered experiences, Miller suggests, ${ }^{7}$ are an important site for the social construction of self in which facets of self and various identities are projected and maintained over time. For her, selves, like cultures, "are not so much preserved in stories as they are created, reworked, and revised through participation in everyday narrative practices that are embedded in and responsive to shifting interpersonal conditions" (Miller, ${ }^{7}$ pp 175-6). Therefore, while the individual autobiographical story that is told at any moment in time may seem unique to the teller, it is, in fact a social creation. As Murray ${ }^{8}$ reminds us: "We are born into a culture which has a ready stock of narratives which we appropriate and apply in our everyday social interaction". In this regard, Somers ${ }^{9}$ makes the following observation about the findings from narrative studies:

Their research is showing us that stories guide action; that people construct identities (however multiple and changing) by locating themselves or being located within a repertoire of emploted stories: that "experience" is constituted through narratives; that people make sense of what has happened and is happening to them by attempting to assemble or in some way to integrate these happenings within one or more narratives; and that people are guided to act in certain ways, and not others, on the basis of the projections, expectations, and memories derived from a multiplicity but ultimately limited repertoire of available social, public, and cultural narratives (Somers, ${ }^{9}$ p 614).

Importantly, as the comments made by Jamie earlier reveal, the understanding of one's self in autobiographical time is embodied. In talking of the "body inescapable"-for example, Connell ${ }^{10}$ notes: "Bodily experience is often central in memories of our lives, and thus our understanding of who and what we are". Likewise, Watson" ${ }^{11}$ observes that "the salience of embodiment can be explained in terms of the relationship that pertains between the body/self and time". Smith and Watson ${ }^{12}$ support these views and point out that the body is a site of autobiographical knowledge because memory itself is embodied. For them, "life narrative is a site of embodied knowledge because autobiographical narrators are embodied subjects. Life narrative inextricably links memory, subjectivity, and the materiality of the body" (Smith et al, ${ }^{12}$ p 37).
What, however, does all this mean for men like Jamie, and what does all this mean for how we understand how narrative works in the lives of people? To explore these issues, we will draw on data generated from a life history study of a small group of men $(n=14)$ who have suffered SCI and become disabled through playing the contact sport of rugby football union. ${ }^{\text {iv }}$

By providing an overview of our findings to date, we seek to illustrate the ways in which certain metaphors, notions of time, and certain kinds of hope, congregate and coalesce within three specific narrative types available to these men within a Western cultural repertoire (see table 1). These are the restitution, chaos, and quest narratives as defined by Frank $^{1}$ that operate to shape the individual experiences of these men following SCI in terms of how they reconstruct body/self relationships over time. By dealing with each of these in turn, we attempt to reveal that narratives do matter when people are faced with disruptive and turning point moments in their lives.

\section{LIVING IN RESTITUTION}

The restitution narrative framed eleven of the men's life stories. According to Frank, (Frank, ${ }^{1}$ p 77) the plot of this narrative has the basic story line: "Yesterday I was healthy, today I'm sick, but tomorrow I'll be healthy again". For the men in our study, this translates as: "Yesterday I was able bodied, today I'm disabled, but tomorrow I'll be able bodied again". Within the frame of this narrative, sporting or "war" metaphors were prominent in these self stories. ${ }^{14}$ The most common was associated with a fight to make a comeback. This is displayed in the following comments by a participant: "One thing rugby taught me was that you have to fight if you are going to get anywhere in life. I've taken this view into how I see disability and myself now. Because, I will walk again and make a comeback. I will fight to make a comeback." The other men also made links with sporting struggles when talking about their disability experience. Often the issue of fighting and making a comeback were related to the notion of a medical cure for SCI. This is evident in the following comment by one of the participants as he thinks about what he would like for his future:

A cure. That is what I want, and I do think that I'll make a comeback and walk again at some point in time. I won't stop fighting until I can do that... If I'm to fight this and make a comeback, then religion or believing that I can mentally make myself walk again is useless. Medical progress is what I want and need...My attitude, right from my days playing rugby up until now is to fight and to never give in. And I do think that giving in is to admit that you'll never walk again or that you won't get some functioning back. So I have to fight and try and make a comeback, get back my old self, and wait for a cure. And, well, I have to be strong. I could never give up or stop fighting, because that again would be like saying that I'm a failure

ivThe methodological and ethical principles informing this study and our work with these men has been described in detail elsewhere in Smith and Sparkes ${ }^{13} 14$ 15; Sparkes, ${ }^{2} 1617$ and Sparkes and Smith. ${ }^{18} 19$ Suffice it to say here that contact was made with participants via an open letter in a newsletter circulated by the English Rugby Football Union's support network for injured players. The participants then contacted us and engaged in a series of confidential, tape recorded interviews that explored their life histories pre and postSCl. At the first interview the ethical principles informing the research were discussed with each participant-for example, participants were told they could withdraw from the interview or the study at any time without having to give any reason, that pseudonyms would be used, and place names changed to preserve anonymity. 


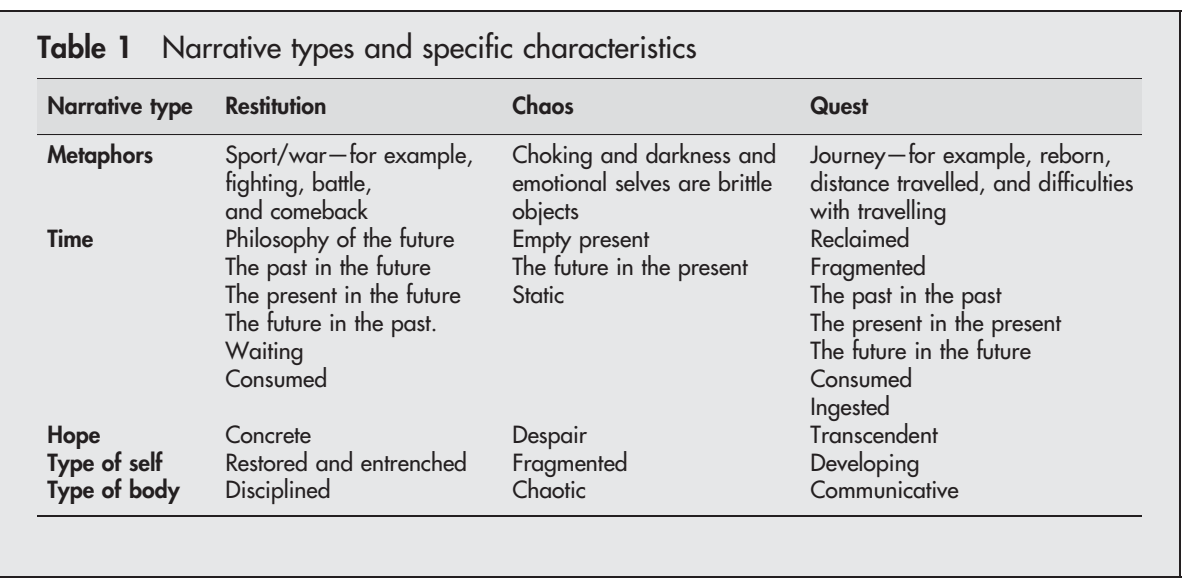

In restitution, another prevalent metaphorical characteristic that strongly shaped the participants' senses of self involved the notion of winning as being cured of disability. Here typical statements included: "Spinal injury is a battle, a struggle...I will win and walk again", and "It's a long battle, but winning, which means walking again, is my aim and it's how I feel and look at life". A further recurring metaphorical strand in the men's stories was one where disability and impairment was defined as an enemy that must be beaten. This is evident in the following comment: "It's like in sport, disability is an enemy that I must beat. But of course I can't do it on my own. I need medicine to find a cure to win". Not surprisingly the body as a battleground metaphor was also commonly used-for example, as one participant stated: "the body is the problem, or at least one of the major problems. I feel as though I'm doing battle with it, if it's getting out of bed, out of the bath, out of my chair...And, it feels as though it's in a relentless battle, one long battle going on inside... One long battle against the body until medicine finds a cure and I can walk again".

The metaphors outlined above are connected to how the self in time is experienced within the restitution narrative. As we have described elsewhere, ${ }^{19}$ autobiographical time within this narrative structure reverberates with what Crossley ${ }^{20}$ terms a philosophy of the future. With respect to disability, this is a temporal orientation that embodies a strategy of minimisation in so far as the person is determined not to let SCI "ruin" the plans they had in the past, or held for the future. People who develop this temporal mode of living also decline to relinquish their routine future orientation, thus refusing to entertain the possibility that they might not walk again. As one of the participants commented:

My aim now is to focus on the future and the light at the end of the tunnel...I try and think about what the future has in store, look to there, and wait until a cure is found. I don't think that's strange, because that's what I want, and you know, it's not how I want to live, like this...I want to, and will walk again, and not far in the future a cure will be found, and it's only there that I see myself.

Framed by the demands of the restitution narrative for themes relating to the technology of a cure and the restorable body/self, a narrative connection is made to the basic temporal orientation of living in the future. For this participant, however, like those others who tell restitution stories, the future takes on different meanings because of the relationships that exist between it and the past and present in his life story. Thus, as described by Roberts, ${ }^{21}$ he experiences, and shifts between, three time tenses connected through the future: the past in the future, the present in the future, and the future in the past.

Making reference to the present in the future-for example, the same participant said: "Well, it's like this. I don't see any use in thinking about the present, my priority is the future... and that is because I see medical advancements being made, even now as we speak." Later in the same interview, however, he made connections with the time tense of the past in the future: "When I first came home I'd got very little use in my arms, I'm the strongest I've ever been now... In maybe ten or fifteen years time, I will be as good as new". Finally, talking about a return to the former self, as well as the future in the past while he waits for a cure that will return him to an able bodied state of being, this participant stated:

\section{Keeping who I was in the past, keep it in mind is something that I need to do if I am to get myself back. And if, as I believe, disability is a temporary situation for me, then I want my old self back because I liked myself then...It's knowing that a cure will be available which helps me to keep my perspective on time in the future. So I look to the future, knowing that the past will return, and recapturing what I had can only be accomplished through what lies in medical advancements, progress. You see, it's a matter of believing that. I just know those days will come back. But the problem is the waiting. I sit here, I can hardly get up and walk can I [laughs]. Well, just waiting, waiting for the future. Just waiting... waiting for the day when I can walk again, be myself.}

These comments signal how this individual narrates time in relation to the future and through the time tenses of the past in the future and the future in the past. They also highlight how defining SCI as temporary fosters a sense of what Charmaz ${ }^{22}$ terms waiting time. That is, the restitution narrative evokes feelings of boredom and time is lost while waiting for the body/self to be restored by advances in biomedicine. As this participant stated: "I don't do a lot, boring existence, just existing...But while it can often seem that I have lots of time on my hands, what you have to remember is that doing the simple things that I never gave much thought about when I could walk, simple things like making a cup of tea, now take up a lot of my time and energy". In this way, waiting time is connected to consumed time, which Seymour ${ }^{3}$ describes as an active and ongoing process whereby quantifiable time becomes a scarce resource that must be re-embodied and constantly managed in order for the body to remain healthy, 
to conform to social imperatives, and to achieve satisfaction in life's activities. In doing so, time becomes a commodity and large amounts of time debits must be set against the value of the outputs.

For the participants who told restitution narratives, the metaphors and the time tenses used sustain a sense of concrete hope. ${ }^{15}$ According to Marcel, ${ }^{23}$ this kind of hope is oriented to specific or material results. It is similar to the typical definition of hope used in the psychological literature as "the positive expectation of realising desirable outcomes". ${ }^{24} \mathrm{~A}$ sense of concrete hope, partly framed by the demands of the restitution narrative is connected to themes relating to the technology of a medical cure and the restorable body/self. An example of this kind of hope is displayed in the following comment of one of the participants:

So becoming disabled was not what I expected, and when it happened I lost everything. It was, is, such a huge crisis and because of it I've lost my life. So, every day I tell myself that I'll walk again. That's what gets me out of bed in the morning. I don't work and don't play sport anymore. So, what do I really have to look forward to? Well, I have hope. It's about every single day hoping that I'll walk again. Which might sound crazy to some people but at least in this miserable existence I have hope...I look forward to the day when I can get everything back that I had before the accident. Stand, and walk. So, really, the main thing that keeps me going is the hope I'll recover. Hope that medicine will keep progressing and find a cure. Hope that there will be an end to all this.

Hope in restitution narratives, therefore, is linked to concrete outcomes that revolve primarily around the discovery of a "cure" via medical and technological advancements in the future. The metanarrative of restitution and concrete hope, along with its associated metaphors and specific time tenses helps create and sustain a restored self and an entrenched self as described by Charmaz ${ }^{\mathrm{V}}$. $^{25}$

These kinds of self are linked to notions of a "comeback" that returns the individual to a former, more desirable, state of being that he had in the past. As such, the individual becomes locked into his past body/self relationships and ways of being in the world through the belief that he will return to this state. To be ready for this return, the body itself must remain disciplined and adhere to various therapeutic regimes so that its former predictability can be embraced when the opportunity arises.

\section{LIVING IN CHAOS}

According to Frank, ${ }^{1}$ chaos narratives are the inverse of restitution narratives, since here the plot imagines life never getting better. These stories are chaotic in their absence of narrative order. They are told by a storyteller who inhabits a chaotic body about how life is experienced - that is, without sequence or discernible causality. Not surprisingly, the self in this narrative is fragmented. Jamie, who suffered his SCI at the T2 level, and who described this moment at the beginning

"The restored self is an identity level at which people expect to return to their former lives following SCl. This is viewed as a "normal" or "natural" response. The men who desire this identity level thus aim both to reconstruct a similar physical self as before and assume continuity with the self they had before they became disabled. Restoring an entrenched self means being wedded to a clear self conception situated in the past. This self represents patterns of action, conviction, and habit built up over the years. These unchanged patterns had been a source of self respect before they experienced SCl and became disabled, and once science has "repaired" their broken bodies, resuming these patterns becomes the person's major objective. of this article, was the one participant who adhered to this narrative form. The metaphors he used when describing his experiences include that of choking.

Before the accident I was happy and life was good. The injury and everything that has happened since has choked any life and happiness out of me. I have nothing now [five second silence]. Am nothing. That's how it is and how it will be... Each day is another day that life is choked out of me. And I feel as though I'm suffocating [seven second silence]. There is no way out. The body is choking me. I don't want any more out of my life. It's over.

Another metaphor for life in chaos used by Jamie is connected to the imagery of solid darkness. When asked how he felt about his life now, he replied:

It's over [fifteen second silence]. I feel removed from my life and from the world outside, as if darkness is closing in on me. That's how it feels. Darkness. But no light shining through. It's difficult, because this feeling is present all the time. I'm on my own. No one. Separated from the outside world. I just watch the fish [in the fish tank]. Darkness is pressing in on all sides [five second silence]. I'm, I don't know...I can't imagine life without darkness. My life is in darkness.

In describing being plunged into chaos and feelings of disconnection, Jamie spoke of the emotional self as a brittle object.

I don't really feel anything [now] about myself. I was shattered by the accident, and everything crumbled away from underneath me. It's still crumbling. I feel myself crumbling.... Not being able to control the body, the environment around you, are aspects of life that you have to live with. No matter how much you try, the situation isn't going to be changed. My life since the accident has fallen apart, and with it all hope crushed [five second silence]. And things are not going to change. My emotions have taken enough and I'm shattered. My emotions are shattered. I'm shattered.

When chaos moves into the foreground of a self narrative, and the self becomes fragmented or shattered, the past, present, and future come under ontological threat. Accordingly, living in chaos results in time being defined as an empty present. This temporal orientation, according to Crossley, ${ }^{20}$ refers to time experienced as a stream of overpowering events. Accordingly, people do not think about, plan, or commit themselves to future possibilities because they are afraid of disappointment. The anxiety associated with such fears means that they fail to commit themselves to various projects and possibilities, and therefore lose all sense of meaning and coherence in their lives. Finally, time caves in.

For Jamie, embodied experiences of time also encompass a time tense of the future in the present, ${ }^{22}$ that is, experiences of time are arranged and placed by "reading" through a combination of the present and future. Here, a future is storied as existing in the chaos of the present. In doing so, and with no plans and few resources, composing a future becomes more and more difficult. Consequently, the future turns out to be uncertain. At the same time, the future is undesired since it is imagined as more chaos, or even worse. Moreover, narrative wreckage engulfs the present. Jamie 
feels trapped in the present. The present swells to fill what is left. The past loses its order and a culturally derived sense of being propelled through time erodes.

\begin{abstract}
Life moves on without me, but, then, I just survive. I don't have ambitions or a future. See the kids grow up, but well it's not the same, then, then what?...I don't do anything of importance. Watch television, not a lot I can do. Nothing [five second pause]. A void, just existing. Then, well, life has stopped. Just, I don't know. Exist in the present, no tomorrow, nothing. I don't know where my life is going. Then, but, it's difficult because time means nothing now... Not a lot to live for...time is, is distorted. Just nowhere. I don't know where I am.
\end{abstract}

Jamie's narrative is also framed by a static view of life. This view of life, as described by Brockmeier, ${ }^{26}$ is a "state of mnemonic paralysis, overpowered by all experience that, like a psychological black hole, absorbs all possible development, all movement that could lead the autobiographical process away from this all consuming experience" (Brockmeier, ${ }^{26} \mathrm{p}$ 68 ). This unchanging story of life, the stretched quality of static time that engulfs the person in a sea of dimensionless time, is displayed in the following comment:

I can't really see a future-I can't. Thinking about, if I could, would be just too overwhelming. I just can't... Life has stopped. Time is frozen. Days, weeks, just merge into one. Nothing changes. Then, I don't know [five second silence]. Things take an eternity to do. So you don't try to do anything anymore. That's why I'm stuck in a rut. In my life nothing changes. Nothing.

The metaphors and time tenses that operate within the chaos narrative leave Jamie with little sense of hope. As he stated: "My life? It's over...I have nothing left to live for. I have no hope of a life. I have nothing. There is no hope for me." In despair, life, is deemed to be meaningless and devoid of purpose.

I'm useless. Nothing. My condition won't improve. No point anymore. I'm no one now. It's a matter of sitting here alone until I die. Life ended for me the day I broke the neck... Believe it or not, I was big and strong. Now I am nothing. Life moves on, without me. That is how it is. How it will always be. I just survive. No ambitions. Nothing...Sometimes I don't think I can go on. I do. But life won't improve. It can only get worse... There is no hope in my life.

In chaos Jamie feels swept along, without control, by life's fundamental contingency. His comments also reveal that when hope is lost, or absent, and certain metaphors and time tenses shape experience, then the belief emerges that one's life is, for all intents and purposes, finished. According to Freeman, ${ }^{27}$ in situations where certain outcomes are anticipated as inevitable, where things cannot be otherwise, individuals may experience what he calls narrative identity foreclosure. This involves the premature conviction that one's life story is effectively over. In such instances, Freeman suggests, if one already knows, or believes one knows what lies ahead, then one may become convinced there is little value in lasting to the very end. Consequently, one's life may seem a foregone conclusion. The individual in this circumstance might feel that he or she can no longer move creatively into the future.

\section{LIVING IN QUEST}

In contrast to restitution and chaos narratives, quest narratives meet suffering head on. They accept impairment and disability and seek to use it. As Frank points out, ${ }^{1}$ just what is quested for may never be wholly clear, but the quest is defined by the person's belief that something is to be gained from the experience. Two of the men in our study (David and Doug) told this type of story about themselves. As we have noted elsewhere, ${ }^{14}$ within a quest narrative journey metaphors are common. The most prevalent metaphor used in this kind of narrative involved the image of being reborn. David stated-for example: "My life has changed since the accident and I'm now on a journey. This isn't a tragic journey though. No, I've been reborn, and have become a better person since becoming disabled." Likewise, Doug commented:

I'm on a different journey, more positive, and have been reborn. I'm learning different things as well, and I've come to think that on this journey, yes disability can be a shattering experience and a tragedy for some people. But it shouldn't be. Why? Because it's an opportunity to explore yourself and become a better person... Still, that doesn't happen overnight, and people stress the negative side of disability, how tragic it all is. And for me, if people see it like that, then how can they improve? Also, part of being reborn and changing into different person...it meant coming to understand that controlling my body and physical functions just isn't possible. I understand that now, and know that it's not perfect, and that on this journey my body will reveal its limitations. But I accept that, and I think that if others can accept it, then maybe people's views on disability might be different and we all might be happier and live better lives.

The "reborn" metaphor suggests that a serious disruption in life's prospects and expectations can offer some people an opportunity to remake themselves. This remaking rejects an overemphasis on bodily predictability in favour of accepting its contingency as part of the fundamental contingency of life. It also rejects the tragedy story line so often associated with becoming disabled. This said, other journey metaphors used by these two men acknowledge that the reconstructing of body/self relationships, and the transcending of one's narrative resources on becoming disabled, is not easy. Thus there was often talk of the distance travelled and the difficulties with travelling that signalled both the notion of progress and a number of embodied problems that can occur on becoming disabled. As David commented: "I've covered a lot of ground...I've made a lot of progress, but there are a lot of ups and downs on the journey I'm on. It isn't easy". Doug also felt he had "moved forward since the accident...come a long way, and made a lot of advancements...progressing, not only individually, but also in my relationships with other people". Doug acknowledged, however, that individual and structural problems can occur as part of the journey: "Along the way there are a lot of problems that can force me off the track...I can't take life for granted. For one, I know that there will be a rocky road ahead of me at some point and obstacles to think about. For now, I have to contend with everyday barriers placed by society, and the occasional emotionally bad day, but who knows what the future will bring."

The metanarrative of progress drawn on by these two men highlights how this complex aspect of journeying is not without risks, difficulties, uncertainties, and descents. Comments made by them also signal that on journeys people may need to reach out to others in order to be helped by them. As such, the point of their lives is not found in solitude but partly in stories and dialogue-in communication and 
community - with others. In this scenario, a more communicative relation with the body emerges in which the body's contingency is not defined as a problem but as a source of possibility. ${ }^{\text {vi }}$

The journey metaphor involving guides, common in both David and Doug's stories, also helps draw attention to this idealised type of body and its empowering potential, as well as to the point that the materiality of the body does matter. As David commented:

People are like guides, helping and guiding people along their journey. So, one really important part of how I've changed has to do with the advice people have offered me over the years, especially since most of it wasn't forced....For instance, l've heard a lot of stories about the disability movement and how society, government policies, access, stuff like that contributes to the problems we face as disabled people...The advice and guidance from some disabled people has also helped me deal with the practical aspects of disability, and learn to understand the limits of what my body can do and cannot do.

As this comment suggests, stories and counternarratives linked with a political narrative and the liberating and empowering potential of the social model of disability can play a significant role in teaching people how to interpret their own disability experiences and the experiences of others. They are also one road to restorying the self over time and developing a more communicative body. ${ }^{1}$

Furthermore, within the quest narrative, there is a reembodiment of time that points toward new opportunities and a chance to remake a life that has passed. ${ }^{20}$ One important aspect of this process includes reclaimed time. For Seymour, ${ }^{3}$ a serious disruption in life's prospects and expectations can offer people an opportunity to remake themselves, in a sense, to reclaim time that has passed. Here, the reality of irrevocable change, the acceptance of contingency as part of the fundamental contingency of life, and the prospect of an unknown future may give immediacy to life that was formerly taken for granted. In this regard, Seymour suggests, "By repossessing the past a person may abandon or rework an earlier life script: the 'cleaned slate' may enable the person to reconstitute him or herself in a more purposeful manner" (Seymour, ${ }^{3}$ p 139). As David commented:

Now I appreciate time more, know that I won't live forever, and I try and savour the moment. See, it's a journey, and the time aspect is not something that I take for granted now...Certainly I don't see disability as a tragedy...As well as the social and access problem...disability is also about living within the limitations, the functional ones, not thinking that you can beat them...Some people spend all their time trying to do more, but I think you can waste time like that. We all only have so much time and wasting it, throwing yourself into doing more, trying to walk again. I don't know because I don't want to sound negative, each has their own way, but sometimes it's best to accept it, use it, and try and enjoy the moment.

vithe communicative body attempts to live a life embedded in relationships that are other regarding. It recognises that bodies are unpredictable and contingency is accepted as normative. It is also productive of desire, needing to nurture and be nurtured by others. Thus, the communicative body relates to others, telling and listening to stories, and is aware of itself and the ongoing production of the body in daily life.
David's notion of reclaimed time draws, in part, on what Brockmeier ${ }^{26}$ identifies as the fragmentary model of time. This is a timeless model that recognises the unpredictable nature of human life and the complexity of self. The future, for David, is not completely uncontrollable, but simply less amenable to control. Acknowledging this, he recognises and challenges the myth of control in relation to the body that prevails in Western cultures. Rejecting this myth and recognising that neither the future nor his body can be totally controlled does not lead David to despondency, or a sense of powerlessness. It simply means that contingency is now accepted as part of the fundamental contingency of life, which is influenced by numerous factors, many of them beyond the control of the individual. Here, as Frank suggests, ${ }^{1}$ bodily predictability comes to be regarded as exceptional, and contingency comes to be accepted as normative. As David said: "I take life as it comes. I don't worry about what the future holds, I mean, I can't control it, not totally anyway, what life throws at you... So I take each day as it comes, and enjoy the moment."

David's connection to a fragmentary narrative model of autobiographical time also links him to certain types of "time tenses". ${ }^{21}$ These include the past in the past, the present in the present, and the future in the future. Making reference first to the past in the past and then shifting to a time tense of the future in the future, David remarked: "The past is in the past and the future, well, as I say you have to recognise that the future is too far ahead, but you are still moving". Later in the interview, however, his accounts of disability are embedded within the present in the present.

I live in the present...I do think that if I lived in the past or thought too much about the future, even if that was concerned with a cure, I don't think that's a good strategy. Why? Well, for starters the present is much more fun... But if I did become preoccupied with the future or even the past, then I think that places a limitation on who you can be...For instance, if I was concerned with the future, then I would probably lose sight of the present and who I am, or am becoming. In that sense, I don't think I would develop as a person because, you know, living in the past or future requires you to have a very specific focus and restricts your opportunities to try out different roles, or experiment with who you are. And in the end I probably would not enjoy the present, not like I do now...I mean, at the end of the day, I live for the here and now and don't take notice of the past, what it meant to me.

Such comments not only signal a life lived in the present, but also suggest that an overemphasis on the past or future might, for some people, lead to a situation that restricts their opportunities to engage with other possible or potential identities as they present themselves. For David, memories of being able bodied are situated in the past, while living as a disabled person occupies the present and helps shape a future. Therefore, time horizons stay close and neither past nor future assumes priority. The present is attended to with a sense of passion, communion, and involvement that enables it to feel fully lived and infused with a certain kind of hope.

In contrast to the restitution narrative that incorporates concrete hope, and the despair of chaos, quest stories foster and embrace transcendent hope. This kind of hope, as defined by Marcel, ${ }^{23}$ is not oriented to achieving a fixed and specific outcome, but instead embraces uncertainty and finitude, celebrating surprise, play, novelty, mystery, and openness to change. In this sense, according to Barnard, "the hopeful person, rather than being defined (or enslaved) by particular wishes, is continually open to the possibility that reality will 
disclose as yet unknown sources of meaning and value" (Barnard, ${ }^{24} \mathrm{p} 48$ ). An example of this kind of hope is evident in the following comment of Doug's as he reflects on how he feels about life now:

Right now I feel great about life and myself...I've developed a much more rounded personality and have become a different person, a much better one after the accident I think, with lots of different sides to me...Okay, for a period of time after the accident I was a mess. But now, I don't view disability as a crisis. I'm on a different path, and I think a better, more fulfilling one. So I'm happy...I don't want to go back to my old life. That doesn't mean that I don't have hopes and dreams. I'm still a hopeful person, but it's not about a cure as many people might think...I don't hope for a cure, and, in my view, it's still very unsure whether one will come.... So, I don't live with the hope for a cure... My view of hope is more about a hope for a better world... But I don't really know what that will mean because I'm still learning. And I think part of the beauty of life is not knowing what will happen in the future. Life is uncertain. I enjoy this though, and feel that part of life is learning to live and enjoy just how mysterious and beautiful it can be.

\section{As David commented:}

Hope for me now is about having opportunities, living in a better society that respects disabled people and values them, and not feeling tied down to one life plan. Actually, I like the fact that my future isn't clear, and I look forward to continuing developing myself, learning, and having hope that I can enjoy life and live with all the problems and surprises that goes with it.

Clearly, for David and Doug, within a quest narrative, specific metaphors and certain time tenses operate to sustain a transcendent sense of hope that shapes their postSCI experiences and their identity construction as disabled men. For them, becoming disabled through sport is reframed as a challenge and an opening to other ways of being. David and Doug have developed more communicative bodies, bodies which place the past securely behind them, live in the present, and see the future as a vista of possibilities, and thus a developing self, as described by Charmaz, ${ }^{25}$ emerges. ${ }^{\text {vi }}$

Here, rather than simply committing to an outcome tied to a cure, and being locked into specific prior activities and former identities, David and Doug are concerned about the direction of their lives as well as the character of the self they shape along the way. Indeed, the two men commit themselves to growing and developing in the future. By opting for a developing self these men emphasise their ability to reconstruct their sense of self over time, they display an openness to change, and show a willingness to explore new identities as possibilities emerge.

\section{SUMMARY}

In this article, we have illustrated the ways in which different types of body/selves, metaphors, notions of time, and certain

viii Rather than commitment to specific prior activities and prior identities, the developing self can be seen here as an identity whereby the direction of the person's life concerns them, as well as the character of the self that they shape. The person also emphasises reconstructing their ability to shift, change, and explore new identities as possibilities emerge. Consequently, they commit themselves to growing and developing in the future. kinds of hope, congregate and coalesce within the restitution, chaos, and quest narratives that shape the individual experiences of fourteen men who have become disabled through sport. These three specific narrative types appear to be important dynamos of their life stories, which energise or impose a structure on what can be experienced and expressed in relation to the lives they could lead.

The restitution narrative leads eleven of the men to articulate sporting/war metaphors, a sense of concrete hope, and a set of time tenses directed toward the future. All of which helps create a restored self and a self that is entrenched, wedded to the former disciplined body which was cultivated in an able body and situated in the past. In contrast to the restitution narrative drawn on by the majority of the men, is the chaos story told by Jamie, which is full of choking and darkness metaphors, despair and lack of hope, and narrative wreckage, which means he lives with the future in the present, and with a present that is empty and static. The result is a fragmented self and the embodiment of chaos. Finally, the quest narrative contains journey metaphors, a sense of transcendent hope, and experiences of time in relation to fragmentary time, reclaimed time. And in this narrative the past is in the past, the present is in the present, and the future is in the future. Framed by this narrative and these notions of time, these kind of metaphors, and this type of hope, SCI is reconfigured as a challenge and an opening to other ways of being as part of a developing self and a more communicative body.

Regardless of whether life is a narrative or narrative is a life, it would seem that narratives do matter for these men in the face of a disruptive and turning point moment in their lives. Indeed, they are an important productive practice for this group of men, after having become disabled through sport. Furthermore, the stories told here reveal that narratives are a useful, humane, even poetically inspired vehicle for conveying some of the richness, depth, and profundity of the human experience to both the storyteller and the listener. ${ }^{27}$ Notably, this dynamic process is embodied. Thus, not only do narratives matter, but the materiality of our individual fleshy bodies as biological entities and our bodies as socially constructed storied projects, also matter. This said, it should be acknowledged that the findings presented here are illuminative rather than definitive. Accordingly, the findings need to be treated with caution and seen as a point of departure for stimulating further questions and investigation. Questions remain-for example, regarding the processes by which the men in our study were drawn toward one particular narrative type over others and how shifts in each of these occur. Also, there needs to be a better understanding of how different types of self, metaphors, notions of time, and certain kinds of hope, congregate and coalesce within the restitution, chaos, and quest narratives over time, and are performed in various contexts before different audiences. This is particularly so given the social nature of story telling and the power differentials involved in this process, which allow some stories to be told and listened to while others are silenced or ignored. Clearly, it is beyond the scope of this article to address such issues. It remains, however, that narrative matters in the lives of individuals and needs to be taken seriously.

\section{Authors' affiliations}

A C Sparkes, B Smith, Qualitative Research Unit, School Sport and Health Sciences, St Luke's Campus, University of Exeter, Exeter, Devon, UK

\section{REFERENCES}

1 Frank AW. The wounded storyteller: body, illness and ethics. Chicago: The University of Chicago Press, 1995. 
2 Sparkes A. Athletic identity: an Achilles heel to the survival of self. Qual Health Res 1998;8:644-64

3 Seymour W. Time and the body: re-embodying time in disability. Journal of Occupational Science 2002:9:135-42.

4 Medved M, Brockmeier J. Making sense of traumatic experiences: telling a life with fragile X syndrome. Qual Health Res 2004; 14:741-59.

5 Murray M. Narrative psychology. In: Smith J, ed. Qualitative psychology. London: Sage, 2003.

6 Brockmeier J, Carbaugh D. Introduction. Narrative and identity:studies in autobiography, self and culture. John Benjamins Pub Co, 2001:15.

7 Miller P. Narrative practices: their role in socialisation and self construction In: Neisser U, Fivush R, eds. The remembering self. Cambridge: Cambridge University Press, 1994.

8 Murray $M$. The storied nature of health and illness. In: Murray $M$, Chamberlain K, eds. Qualitative health psychology. London: Sage, 1999:53.

9 Somers $\mathbf{M}$. The narrative constitution of identity: a relational and network approach. Theory Soc 1994;23:635-49.

10 Connell R. Masculinities. Cambridge: Polity Press, 1995:53.

11 Watson J. Male bodies. Buckingham: Open University Press, 2000:109.

12 Smith S, Watson J. Reading autobiography. Minneapolis: University of Minnesota Press, 2001.

13 Smith B, Sparkes A. Men, sport, spinal cord injury, and the construction of coherence: narrative practice in action. Qualitative Research 2002;2:143-71.

14 Smith B, Sparkes A. Men, sport, and spinal cord injury: an analysis of metaphors and narrative types. Disabil Soc 2004; 19:509-612.

15 Smith B, Sparkes A. Men, sport, spinal cord injury and narratives of hope. Social science and medicine 2005;61:1095-105.
16 Sparkes A. Exploring body narratives. Sport, Education and Society 1999;4:17-30.

17 Sparkes A. Narrative analysis: exploring the whats and hows of personal stories. In: Holloway I, ed. Qualitative research in health care. Buckingham: Open University Books 2005:191-209.

18 Sparkes A, Smith B. Sport, spinal cord injuries, embodied masculinities, and narrative identity dilemmas. Men and Masculinities 2002;4:258-85.

19 Sparkes A, Smith B. Men, sport, spinal cord injury and narrative time. Qualitative Research 2003;3:295-320.

20 Crossley M. Introducing narrative psychology. Buckingham: Open University Press, 2000.

21 Roberts B. Some thoughts on time perspectives and auto/biography. Auto/ Biography 1999; VII: 21-5.

22 Charmaz K. Good days, bad days: the self in chronic illness and time. New Brunswick, NJ: Rutgers University Press, 1991.

23 Marcel G. Homo viator [trans Craufurd E]. New York: Harper and Row, 1962.

24 Barnard D. Chronic illness and the dynamics of hoping. In: Toombs K Barnard D, Carson R, eds. Chronic illness: from experience to policy. Bloomington: Indiana University Press, 1995:47.

25 Charmaz K. Struggling for a self: identity levels of the chronically ill. In: Roth J, Conrad $\mathrm{P}$, eds. Research in the sociology of health care:a research manual [vol 6]. Greenwich, CT: JAI Press Inc, 1987.

26 Brockmeier J. Autobiographical time. Narrative Inquiry 2000;19:51-73.

27 Freeman $M$. When the story's over: narrative foreclosure and the possibility of self renewal. In: Andrews M, Day Sclater S, Squire C, et al, eds. Lines of narrative. London: Routledge, 2003.

\section{CORRESPONDENCE}

\section{We are all artists}

The difficulties encountered by McNaughton and Evans in addressing the question 'Why pay attention to the artist?' are those created by disciplinary boundaries and a useful answer is unlikely without stepping outside the academic discipline. ${ }^{1}$ It is in the nature of academic disciplines to parcel up life. Each then uses its 'discursive, reflective and primarily cognitive' faculties to wrap and unwrap the parcel and pass it around at conferences! However, the content and wrappings, so well known in one discipline, might be puzzling to another. For instance, within the same world of health and suffering, Medical Humanities sees the artist and clinician as different people, whereas in Narrative Medicine (so near and yet so far) they are the same. In the former, the artist does art (or at least their art is used) in a medical setting, and in the latter, the artist within the practitioner co-creates the work with a patient. Or so it seems.

As a practising NHS general practitioner and researcher, aspiring writer of stage plays, and husband of a painter, I offer my view from elsewhere. For me, the creative process involved in writing drama is closely similar to that in the consultation, especially when the play is written for a particular creative production team (including the binning of the offering if they don't like it!). There is the same close attention to language and context, the same weaving of story, the same collective search for meaning that might help someone, anyone, to move on - including myself. In this, I am with the narrative folk. I see my role as the artist. The science and technology I use in the consultation is to further the art of medicine that I try to practise - just as some of my writer friends use science and technology in their multimedia projects.
So why pay attention to the artist? Because the artist and clinician are one and the same, varying only in the extent of their use of artistic insights and practices. In fact, as John Ruskin insisted, we are all artists - even academics! All we need is inspiration. Show us what is possible! Be a marriage broker between medicine, and the arts and humanities. Help us to really understand what Wassily Kandinsky meant when he wrote of the artist at a spiritual level: 'He sees and points the way.'2

W House

St Augustines Practice, 4 Station Road, Keynsham, Bristol BS31 2BN, UK; william.house@gp-L81045.nhs.uk

\section{References}

1 MacNaughton RJ, Evans HM. Why pay attention to the artist? J Med Ethics: Medical Humanities 2005;31:1-2.

2 Kandinsky W. Concerning the Spiritual in Art New York, Dover 1977, p 4. 